\title{
Antifungal activity of tautomycin and related compounds against Sclerotinia sclerotiorum
}

\author{
Xiaolong Chen, Xiaohui Zhu, Yicheng Ding and Yinchu Shen
}

The potential of tautomycin to control oilseed rape stem rot was investigated in this paper. Tautomycin produced by Streptomyces spiroverticillatus strongly inhibited Sclerotinia sclerotiorum, which causes oilseed rape stem rot. Tautomycin showed great inhibition of the mycelial growth of $S$. sclerotiorum on potato dextrose agar (PDA) plates. The values of EC ${ }_{50}$ and MIC were $3.26 \times 10^{-4} \mathrm{~mm}$ and $6.52 \times 10^{-4} \mathrm{~mm}$, respectively. Tautomycin treatment also resulted in morphological abnormalities of $S$. sclerotiorum such as hyphal swellings and abnormally branched shapes, which were observed microscopically. Sclerotia of $S$. sclerotiorum soaked in the tautomycin solution for $24 \mathrm{~h}$ remained viable, but their ability to undergo myceliogenic germination on PDA plates was completely inhibited when the concentration of tautomycin reached $6.52 \times 10^{-4} \mathrm{~mm}$. Tautomycin-treated oilseed rape leaves were found to have a low incidence of leaf blight caused by $S$. sclerotiorum. The activity of the protein phosphatase (PP) in S. sclerotiorum decreased by $41.6 \%$ and $52.6 \%$ when treated with $3.30 \times 10^{-4} \mathrm{~mm}$ and $6.52 \times 10^{-4} \mathrm{~mm}$ tautomycin, respectively. Cellular constituents also leaked from $S$. sclerotiorum cells incubated with tautomycin. The results suggest that the antimicrobial activity of tautomycin is due to the inhibition of the PP and then a change of membrane permeability. This paper also investigated related compounds that possess either a maleic anhydride or maleic acid moiety. Results showed 2,3-dimethylmaleic anhydride, diphenylmaleic anhydride and dimethyl maleate demonstrated significant activity against $S$. sclerotiorum. The values of $\mathrm{EC}_{50}$ for these three compounds were $0.31 \mathrm{~mm}, 0.15 \mathrm{~mm}$ and $3.99 \mathrm{~mm}$, respectively. The MIC values obtained for these compounds were $1.11 \mathrm{~mm}, 0.56 \mathrm{~mm}$ and $9.58 \mathrm{~mm}$, respectively. The Journal of Antibiotics (2011) 64, 563-569; doi:10.1038/ja.2011.55; published online 20 July 2011

Keywords: inhibition; maleic anhydride; Sclerotinia sclerotiorum; tautomycin

\section{INTRODUCTION}

Sclerotinia sclerotiorum (Lib.) de Bary is considered to be an important fungal plant pathogen. This necrotrophic pathogen shows little host specificity and has a host range that includes over 400 primarily dicotyledonous plant species. ${ }^{1}$ The pathogen can cause serious losses in yield and quality of oilseed rape in many countries. It is difficult to breed varieties of oilseed rape resistant to leaf blight disease caused by $S$. sclerotiorum, as resistance is regulated by multiple genes. $^{2}$ The appearance of resistant strains in several countries including the United States and Mexico has raised concerns about the use of chemical fungicides. ${ }^{2}$ The increasing occurrence of plant pathogens that are insensitive to commercial fungicides continues to fuel the exploration of new natural product-based fungicides.

Tautomycin (Figure 1), a novel intracellular natural product was isolated and identified at the end of the 1980s from the broth of Streptomyces spiroverticillatus in China. ${ }^{3,4}$ Its chemical structure contains a maleic anhydride moiety. Tautomycin significantly inhibits microbial growth $\left(\mathrm{MIC}=6.52 \times 10^{-4} \mathrm{~mm}\right)$, has strong antifungal activity against $S$. sclerotiorum, and inhibits types 1 and $2 \mathrm{~A}$ of protein phosphatase (PP) activity. ${ }^{4-9}$ Potent biological activities of tautomycin has stimulated other research groups to investigate its biosynthesis ${ }^{10}$ and chemical synthesis. ${ }^{11}$ However, it was not commercially produced as the fungicide against $S$. sclerotiorum because of its high toxicity to mice $\left(\mathrm{LD}_{50}=7.5 \mathrm{mg} \mathrm{kg}^{-1}\right.$, orally). ${ }^{3}$ The mechanism of biocontrol in S. sclerotiorum has not been determined. Natural products that contain a maleic anhydride or maleic acid moiety are biologically active, demonstrating activities such as antibiotic and enzyme inhibition activities. For example, zopfiellin ${ }^{12,13}$ has been produced on a commercial scale as an antifungal agent against Botrytis cinerea. Cornexistin $^{14}$ and hydroxycornexistin ${ }^{15}$ are new microbial post-emergence herbicides with selectivity to corn. Structure-activity studies on natural products containing a maleic anhydride moiety confirm the essential role this moiety has for biological activity. ${ }^{5}$ Therefore, more studies are needed to further verify the hypothesis.

The objectives of this study were as follows: (1) to detect the inhibitory effect of tautomycin on mycelial growth, the germination and production of sclerotia of S. sclerotiorum; (2) to preliminarily investigate the mechanism of the antifungal activity against S. sclerotiorum; (3) to investigate the activity of compounds with maleic anhydride structure against $S$. sclerotiorum in vitro in order to 


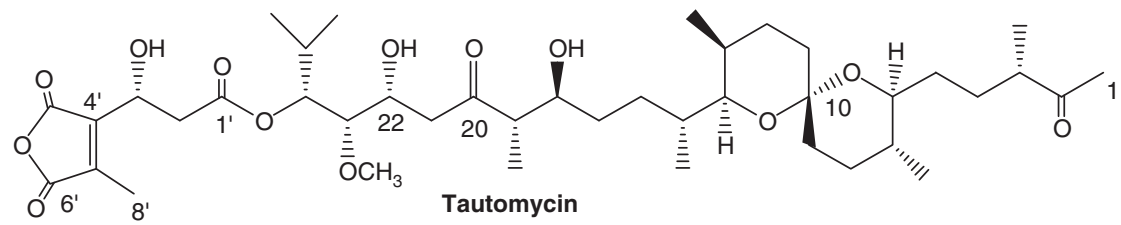<smiles>CCCCC1CC2=C(C(=O)OC2=O)C(C(O)CCCC)CC2=C1C(=O)OC2=O</smiles><smiles></smiles>

Cornexistin<smiles></smiles>

Hydroxycornexistin

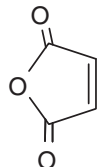

Maleic anhydride<smiles>CC1=C(C)C(=O)OC1=O</smiles>

2,3-Dimethyl maleic anhydride<smiles>O=C1C=C(c2ccccc2)C(=O)O1</smiles>

Phenylmaleic anhydride<smiles>Cc1ccc2c(c1)C(=O)OC2=O</smiles>

4-Methylphthalic anhydride<smiles>O=C1C=C(Br)C(=O)O1</smiles>

Bromomaleic anhydride<smiles>O=C1OC(=O)c2ccccc21</smiles>

Phthalic anhydride<smiles>O=C1OC(=O)c2c(F)c(F)c(F)c(F)c21</smiles>

Tetrafluorophthalic anhydride<smiles>O=C1OC(=O)c2c(F)ccc(F)c21</smiles>

3,6-Difluorophthalic anhydride<smiles>O=C1OC(=O)c2c1ccc(Cl)c2Cl</smiles>

Dichloromaleic anhydride<smiles>O=C(O)c1ccc2c(c1)C(=O)OC2=O</smiles>

Trimellitic anhydride<smiles>O=C1OC(=O)c2c(F)cccc21</smiles>

3-Fluorophthalic anhydride<smiles>O=C1OC(=O)C(c2ccccc2)=C1c1ccccc1</smiles><smiles>O=C1OC(=O)c2cc(Cl)c(Cl)cc21</smiles>

4,5-Dichlorophthalic anhydride<smiles>O=C1OC(=O)c2c(Cl)ccc(Cl)c21</smiles>

3,6-Dichlorophthalic anhydride

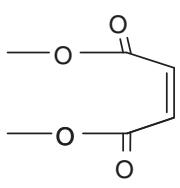

Dimethyl maleate

Figure 1 Chemical structures of tautomycin and related compounds. 
provide a theoretical basis for structure modification of tautomycin and fungicide development.

\section{MATERIALS AND METHODS}

Fungal strain, media and culture conditions

S. sclerotiorum used in this study was isolated from Sclerotia of S. sclerotiorum collected from a diseased plant of oilseed rape in Zhejiang, People's Republic of China. Cultural media were potato dextrose agar (PDA) and potato dextrose broth (PDB). Both PDA and PDB were made of fresh potato using the procedures described by Fang. ${ }^{16}$ Sclerotia were placed at the center of sterilized 9 - $\mathrm{cm}$ petri dishes using PDA medium. The dishes were incubated at $25^{\circ} \mathrm{C}$ for $2-3$ days until the mycelium covered the dishes completely. Agar plates for the inoculum plug were cut from the hyphal tips of the mycelium with a $6-\mathrm{mm}$ sterilized cork borer

A 6-mm inoculum plug was inoculated in $50 \mathrm{ml}$ of PDB in an Erlenmeyer flask $(250 \mathrm{ml})$. The cultures were incubated at $25^{\circ} \mathrm{C}$ on a rotary shaker (200 r.p.m.) for 4 to 7 days. The hyphae were collected for light microscopy.

Streptomyces spiroverticillatus 0092 was kindly supplied by Shanghai Pesticide Research Institute. The strain was maintained by us in tubes with glycerol and transferred to the slants of Gauze 1 medium, and incubated at $28^{\circ} \mathrm{C}$ for about 10 days until the spores were ripe.

\section{Preparation of solutions of tautomycin and other related compounds}

Samples of tautomycin were prepared according to Cheng et al. ${ }^{4}$ with modification. Tautomycin was produced with fermentation of S. spiroverticillatus at $28^{\circ} \mathrm{C}$ for $84 \mathrm{~h}$ in a 30-1 mechanically stirred tank reactor (BioFLO 110, New Brunswick Scientific, Edison, NJ, USA) containing 201 of a medium, which was composed of $2 \%$ glucose, $1 \%$ soluble starch, $0.1 \%$ meat extract, $0.4 \%$ dry yeast, $2.5 \%$ soybean cake powder, $0.2 \% \mathrm{NaCl}$ and $0.005 \% \mathrm{~K}_{2} \mathrm{HPO}_{4}$ (All medium ingredients used in the study were purchased in the local market.). Broth (101) was extracted with the same volume of EtOAc at pH 3.0 to 4.0 adjusted with $1 \mathrm{~m} \mathrm{HCl}$ solution for three times and the extracts were washed with 51 water and 101 brine, then dehydrated with $\mathrm{Na}_{2} \mathrm{SO}_{4}$ and concentrated to dryness to achieve the oily residue. The residue was dissolved in 11 alkaline water at $\mathrm{pH} 8.0$ to 8.5 adjusted with $1 \mathrm{M} \mathrm{NaOH}$ and the insoluble portion was removed by centrifuge. Water phase was extracted with the same volume of EtOAc again at $\mathrm{pH} 3.0-4.0$ adjusted with $1 \mathrm{M} \mathrm{HCl}$ for three times, and the organic phase was combined and washed with 0.51 water and 11 brine, then dehydrated with $\mathrm{Na}_{2} \mathrm{SO}_{4}$ and concentrated to give the sample. The sample was dissolved with $50 \mathrm{ml} \mathrm{MeOH}$ and further purified by preparative liquid chromatography $\left(\mathrm{C}_{18}, \mathrm{MeOH}\right.$ :water $=8: 2$ plus $0.1 \%$ TFA, Waters, Burnsville, $\mathrm{MN}$, USA). The peaks with biological activity against S. sclerotiorum $^{9}$ were collected and analyzed by re-chromatography in the same condition. There were only two peaks in the mixture, as found in previous work. ${ }^{4}$ The mixture was used as standard tautomycin. Tautomycin solutions used for biological assay were prepared by diluting the stock solution in water to required concentrations.

Maleic anhydride, phthalic anhydride, phenyl maleic anhydride, tetrafluorophthalic anhydride, 3-fluorophthalic anhydride, 4-methylphthalic anhydride, 3,6-difluorophthalic anhydride, diphenylmaleic anhydride, bromomaleic anhydride, 4,5-dichlorophthalic anhydride, 3,6-dichlorophthalic anhydride, 2,3dichloromaleic anhydride and dimethyl maleate were all purchased from Sigma (St Louis, MO, USA). Dimethyl maleic anhydride and trimellitic anhydride were purchased from Alfa Aesar (Ward Hill, MA, USA). The compounds were dissolved with acetone or water, and the pHs of the solutions were adjusted to 7.0 in order to be used in all bioassays. Acetone was added to the control when it was used to dissolve a chemical sample.

\section{Suppression of mycelial growth of $S$. sclerotiorum by tautomycin and other related compounds}

Tautomycin samples were mixed with the PDA to produce a series of concentrations in the final test solution of $1.3 \times 10^{-4}, 2.6 \times 10^{-4}, 3.9 \times 10^{-4}$, $5.2 \times 10^{-4}$ and $6.5 \times 10^{-4} \mathrm{~mm}$. Tautomycin-free agar containing only acetone was used as the control. To simplify the procedure, $9 \mathrm{ml}$ PDA with $1 \mathrm{ml}$ tautomycin sample was poured into a 9-cm petri dish. After the petri dishes with the mixed medium were cooled to room temperature, 6-mm inoculum plug was inoculated with the mycelium below at the center of the dishes. Triplicates for each treatment were used. After incubation at $25^{\circ} \mathrm{C}$ under fluorescent light ( $12 \mathrm{~h}$ per day) for 2 days, the colony diameter of S. sclerotiorum in each dish was assessed by making two measurements at right angles. Inhibition of growth of $S$. sclerotiorum by tautomycin was calculated using the formula: inhibition of growth $(\%)=\left(D_{\mathrm{ck}}-D\right) /\left(D_{\mathrm{ck}}-6\right) \times 100$, where $D_{\mathrm{ck}}$ represents the average colony diameter of the control, $D$ represents the average colony diameter in the treatment of compound and 6 represents the diameter of the inoculum plug (in $\mathrm{mm}$ ).

The solutions of the related compounds were mixed with PDA to obtain final concentrations that ranged from 0.01 to $1000 \mathrm{~mm}$. 2,3-Dimethylmaleic anhydride was incorporated into PDA at a final concentration of $0,0.16,0.32$, $0.48,0.64,0.80,0.96$ and $1.12 \mathrm{~mm}$; diphenylmaleic anhydride with a final concentration of $0,0.08,0.16,0.24,0.32,0.40,0.48$ and $0.56 \mathrm{~mm}$ and dimethyl maleate with a final concentration of $0,1.60,3.20,4.80,6.40,8.00$ and $9.60 \mathrm{~mm}$. The same procedures described above were used for testing these compounds. The experiment was repeated three times.

\section{Effect of tautomycin and other related compounds on the formation of sclerotia}

The four compounds being tested were mixed with PDA to produce a series of different final concentrations mentioned above (suppression of mycelial growth of S. sclerotiorum by tautomycin and other related compounds). A 6-mm inoculum plug was inoculated with the mycelium below at the center of the dishes. The number of sclerotia was counted and the average number of the three PDA plates was calculated after 10 days. There were nine dishes (replicates) for each treatment. The experiments were repeated for three times.

\section{Suppression of myceliogenic germination of sclerotia of}

\section{S. sclerotiorum by tautomycin and other related compounds}

Mycelial plugs of S. sclerotiorum were inoculated on PDA in petri dishes, and the dishes were incubated at $25^{\circ} \mathrm{C}$. After 2 weeks, sclerotia of S. sclerotiorum formed in each dish were harvested and air-dried at room temperature (20$25^{\circ} \mathrm{C}$ ). Twenty sclerotia of S. sclerotiorum were submerged in $25 \mathrm{ml}$ tautomycin solution $\left(6.52 \times 10^{-4} \mathrm{~mm}\right)$ for $24 \mathrm{~h}$ (submerged in distilled water as a control). For 2,3-dimethylmaleic anhydride, diphenylmaleic anhydride and dimethyl maleate, sclerotia of $S$. sclerotiorum were submerged in each solution with a final concentration of 1.12, 0.56 and $9.6 \mathrm{~mm}$, respectively. The sclerotia were collected, blotted dry on sterilized paper towel surface-sterilized in $0.1 \%(\mathrm{w} / \mathrm{v})$ $\mathrm{HgCl}_{2}$ for $5 \mathrm{~min}$. Then the sclerotia were rinsed in sterile distilled water for three times ( 1 min each time) and individually inoculated on PDA in petri dishes $(9 \mathrm{~cm}$ diameter) (four sclerotia per dish). The sclerotial germination and the colony diameter of $S$. sclerotiorum around each sclerotium were recorded after incubation at $25^{\circ} \mathrm{C}$ in the dark for 2,3 and 4 days. A sclerotium was considered to have germinated when white, cottony mycelia appeared on the sclerotial surface or on the agar medium. The experiment was repeated for three times.

\section{Effect of tautomycin on incidence of leaf blight of oilseed rape caused by $S$. sclerotiorum}

Seeds of oilseed rape Zhong You No.4 were sown in soil in pots. Leaves $(5 \times 6 \mathrm{~cm}, L \times W)$ were excised from the central part of each plant. Eighteen detached leaves were randomly selected and placed in six rows (three leaves per row) on moist towels in an enamelware tray. A volume of $1 \mathrm{ml}$ of the tautomycin solution (with different concentrations: $3.26,6.52,13.04,26.08$, $52.16 \times 10^{-4} \mathrm{~mm}$ ) was spread evenly on the surface of leaves of oilseed rape in a tray using a brush, three leaves for each concentration. Water was directly spread on three leaves of oilseed rape in a tray also at about $1 \mathrm{ml}$ per leaf as control. The treated trays were left at room temperature $\left(20-25^{\circ} \mathrm{C}\right)$ to allow the evaporation of the excess water from the surface of the leaves of oilseed rape. A 6-mm mycelial agar plug of S. sclerotiorum was inoculated in the center of the leaf. The trays were sealed with a clear plastic film to maintain high moisture and were incubated in a chamber at $25^{\circ} \mathrm{C}$ under fluorescent light $(12 \mathrm{~h}$ per day). After 4 days, the development of the pathogen was observed. The bioassay was repeated four times. 
Effect of tautomycin on the protein phosphatase in S. sclerotiorum Sample preparation of the protein phosphatase solution. S. sclerotiorum was incubated in PDB for 5 days and tautomycin (water solution) was added to a final concentration in the broth using water as the control and incubated for another day. The biomass was collected by centrifugation at 10000 r.p.m. for $10 \mathrm{~min}$ and $4{ }^{\circ} \mathrm{C}$. The biomass was rinsed with $0.1 \mathrm{moll}^{-1}$ acetate buffer at $\mathrm{pH}$ 5.0 and centrifuged again for two times. The biomass was suspended in $0.1 \mathrm{moll}^{-1}$ acetate buffer at $\mathrm{pH} 5.0$ and was ultrasonicated for $30 \mathrm{~min}$. The suspension was centrifuged at 15000 r.p.m. for $10 \mathrm{~min}$ and $4{ }^{\circ} \mathrm{C}$. The supernatant was collected as the sample of the PP solution.

Assay of the protein phosphatase. The assay of the PP was prepared according to reference ${ }^{17}$ with modification. The phosphatase activity was assayed in $2.0 \mathrm{ml}$ of a reaction mixture containing acetate buffer and $p$-nitrophenyl phosphate with adding $20 \mu \mathrm{l}$ the sample of the PP solution. The reaction was performed at $37^{\circ} \mathrm{C}$, terminated after $40 \mathrm{~min}$ by the addition of $5 \mathrm{ml}$ of $0.2 \mathrm{moll}^{-1} \mathrm{NaOH}$, and read at the wavelength $405 \mathrm{~nm}$. In the experiment, $p$-nitrophenyl phosphate was purchased from Sigma-Aldrich.

\section{Effect of tautomycin on the physicochemical changes of S. sclerotiorum}

The hyphal form was observed with the light microscope. The hyphae were collected after 2 days of fermentation in PDB and incubated with the different concentrations of tautomycin for $24 \mathrm{~h}$.

The membrane permeability was investigated with the change of electrical conductivity of broth. ${ }^{18}$ The electrical conductivity was analyzed with a conductimeter (DDS-307A, Shanghai Precision and Scientific Instrument, Shanghai, China). The hyphae were incubated in PDB for 2 days at $25^{\circ} \mathrm{C}$ and shaken at 150 r.p.m., and centrifuged at 10000 r.p.m. for $10 \mathrm{~min}$ and $4^{\circ} \mathrm{C}$. The hyphae were collected, rinsed with deionized water and centrifuged under the same conditions as above for two times. Then the biomass was suspended in the deionized water or in the tautomycin solution and incubated in the rotating shaker at $25^{\circ} \mathrm{C}$ and 150 r.p.m. for different time. The relative conductivity was calculated as follows:

- Relative conductivity $=(\mathrm{J} 1-\mathrm{J} 0) /(\mathrm{J} 2-\mathrm{J} 0)$

- J0: electrical conductivity of broth at zero hour.

- J1: electrical conductivity of broth at few hours.

- J2: electrical conductivity of broth after boiling for $15 \mathrm{~min}$ at some hours.

- The data were obtained by repeating for three times. The average was taken.

\section{Statistical analysis}

Analysis of variance (SAS Institute, Cary, NC, USA, Version 8.0, 1999) was used to determine the statistical significance of differences among treatments in each bioassay. The \% data on inhibition of growth of S. sclerotiorum in each replicate was arcsine-transformed to angular data before analysis of variance. Means for different treatments in each bioassay or trial were separated using the least significant difference test at $P=0.05$ level.

\section{RESULTS}

Suppression of mycelial growth of $S$. sclerotiorum by tautomycin and other related compounds

The antifungal activity of tautomycin and 15 other related chemical compounds were evaluated. Tautomycin and three other samples (Figure 1) significantly inhibited the mycelial growth of S. sclerotiorum and showed dose-dependent inhibitory effects on mycelial growth (Figure 2) in vitro, with $\mathrm{EC}_{50}$ values of $3.26 \times 10^{-4} \mathrm{~mm}$ for tautomycin (1); $0.31 \mathrm{~mm}$ for 2,3-dimethyl maleic anhydride (2); $0.15 \mathrm{~mm}$ for diphenylmaleic anhydride (3); $3.99 \mathrm{~mm}$ for dimethyl
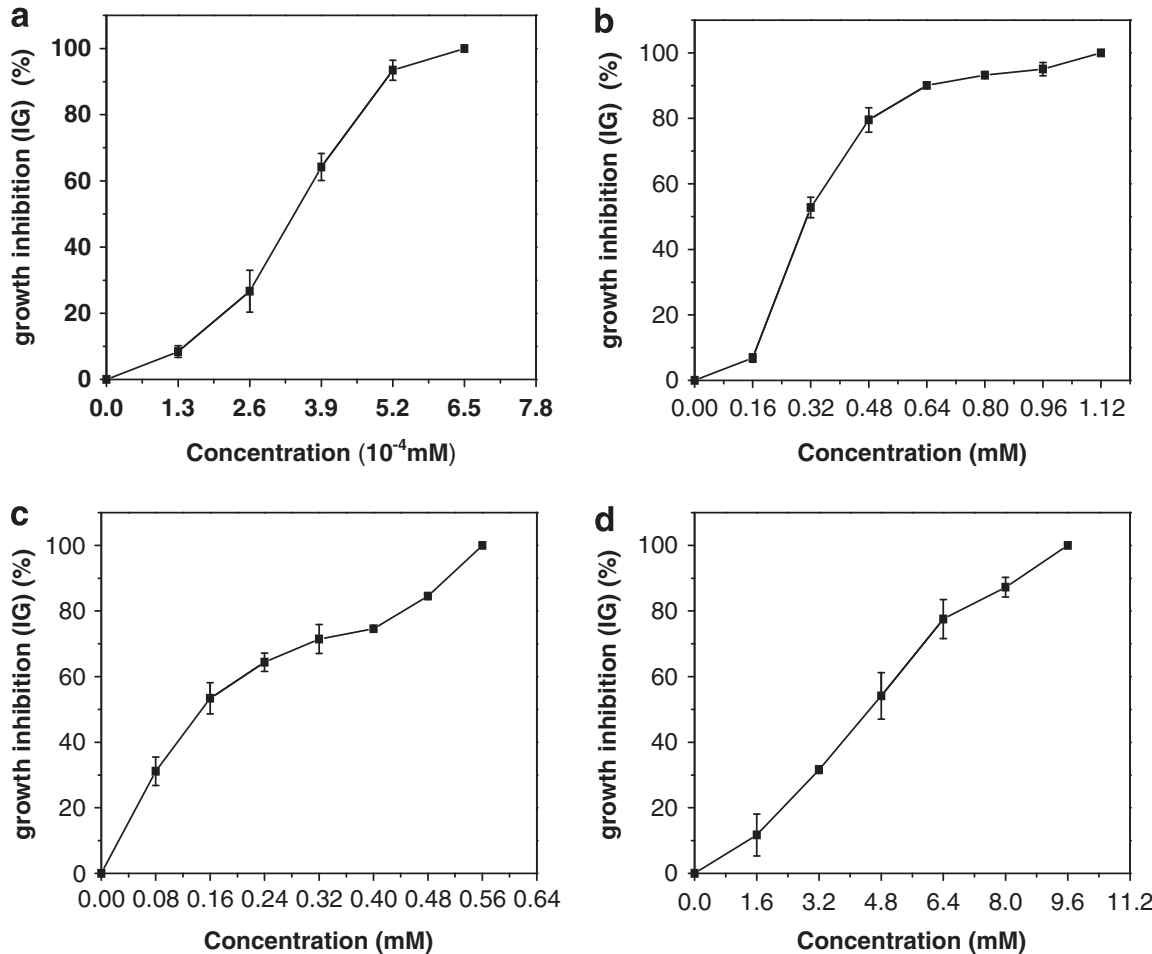

Figure 2 Effect of the concentration of tautomycin (a), 2,3-dimethyl maleic anhydride (b), diphenylmaleic anhydride (c) and dimethyl maleate (d) on inhibition of growth of $S$. sclerotiorum. Each data point is the average of nine replicates. Means with the same letter are not significantly $(P>0.05)$ different according to the least significant different test. 
maleate (4) (Table 1). The other 11 compounds did not display obvious inhibitory action on mycelial growth of $S$. sclerotiorum. Microscopic assessments of the hyphae indicated that control mycelia

Table 1 Inhibitory effect of compounds on mycelial growth of Streptomyces sclerotiorum

\begin{tabular}{lcc}
\hline Compounds & $E C_{50}(\mathrm{~mm})$ & MIC (mM) \\
\hline Tautomycin & $3.26 \times 10^{-4}$ & $6.52 \times 10^{-4}$ \\
2,3-Dimethylmaleic anhydride & 0.31 & 1.11 \\
Diphenylmaleic anhydride & 0.15 & 0.56 \\
Dimethyl maleate & 3.99 & 9.58 \\
Bromomaleic anhydride & 43.05 & 107.63 \\
Maleic anhydride & $>1000$ & $>1000$ \\
Phthalic anhydride & $>1000$ & $>1000$ \\
Trimellitic anhydride & $>1000$ & $>1000$ \\
4-Methylphthalic anhydride & $>1000$ & $>1000$ \\
Phenylmaleic anhydride & $>1000$ & $>1000$ \\
Tetrafluorophthalic anhydride & $>1000$ & $>1000$ \\
3-Fluorophthalic anhydride & $>1000$ & $>1000$ \\
3,6-Difluorophthalic anhydride & $>1000$ & $>1000$ \\
Dichlormaleic anhydride & $>1000$ & $>1000$ \\
4,5-Dichlorophthalic anhydride & $>1000$ & $>1000$ \\
3,6-Dichlorophthalic anhydride & $>1000$ & $>1000$ \\
\hline
\end{tabular}
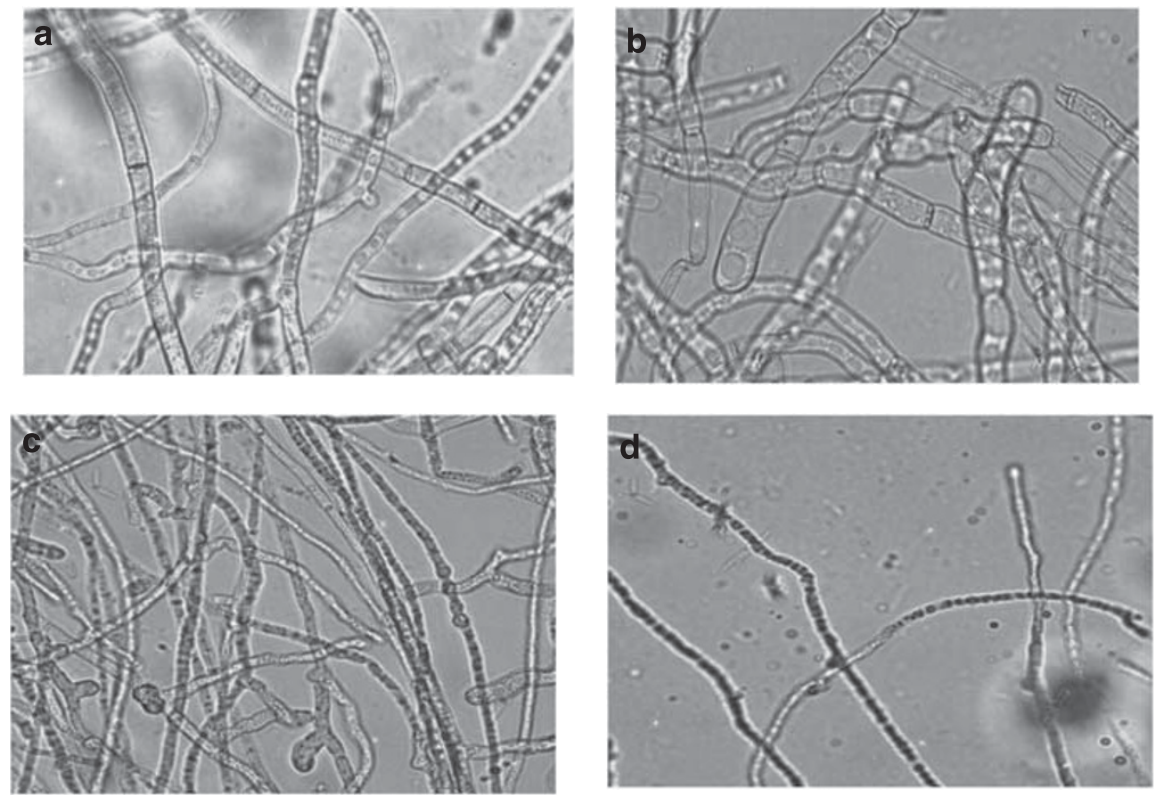

Figure 3 Morphology of hyphae under the influence of tautomycin. Concentration of tautomycin (10-3 mm): $\mathbf{a}=0$ (control), $\mathbf{b}=1.3, \mathbf{c}=2.6$ and $\mathbf{d}=3.9$.

Table 2 Effect of tautomycin and other related active compounds on the formation of sclerotia ${ }^{a}$

\begin{tabular}{|c|c|c|c|c|c|c|c|c|}
\hline \multirow{2}{*}{$\frac{\text { Compounds }}{\text { Tautomycin }}$} & \multirow[b]{2}{*}{ Concentration (10-4 $\mathrm{mm})$} & \multicolumn{7}{|c|}{ Concentration and sclerotia formation } \\
\hline & & 0 & 1.3 & 2.6 & 3.9 & 5.2 & 6.5 & \\
\hline & Sclerotia formation & 45 & 35 & 13 & 3 & 2 & 0 & \\
\hline \multirow[t]{2}{*}{ 2,3-Dimethylmaleic anhydride } & Concentration $\left(10^{-2} \mathrm{~mm}\right)$ & 0 & 7.9 & 15.8 & 23.7 & 31.6 & 39.5 & \\
\hline & Sclerotia formation & 26 & 23 & 26 & 9 & 3 & 2 & \\
\hline \multirow[t]{2}{*}{ Diphenylmaleic anhydride } & Concentration $\left(10^{-2} \mathrm{~mm}\right)$ & 0 & 8 & 16 & 24 & 32 & 40 & 48 \\
\hline & Sclerotia formation & 52 & 41 & 37 & 50 & 57 & 47 & 17 \\
\hline \multirow[t]{2}{*}{ Dimethyl maleate } & Concentration (mм) & 0 & 1.6 & 3.2 & 4.8 & 6.4 & 8.0 & 9.6 \\
\hline & Sclerotia formation & 43 & 49 & 74 & 43 & 34 & 42 & 16 \\
\hline
\end{tabular}

The number of Sclerotia formation is the average of nine replicates. 
after incubation for $96 \mathrm{~h}$ (Table 3). Sclerotia of S. sclerotiorum, treated with 2,3-dimethylmaleic anhydride, diphenyl-maleic anhydride and dimethyl maleate for $24 \mathrm{~h}$, geminated at levels of $70 \%, 100 \%$ and $100 \%$, respectively, after incubation for $96 \mathrm{~h}$.

\section{Effect of tautomycin on incidence of leaf blight of oilseed rape caused by $S$. sclerotiorum}

As shown in Figure 4, the incidence of leaf blight of oilseed rape caused by $S$. sclerotiorum was significantly reduced by treatment with tautomycin. After inoculating for 4 days, the whole leaf turned yellow in water treatment control. Compared with the control, no differences were observed in the treatments with $3.26 \times 10^{-4} \mathrm{~mm}$ tautomycin. With increasing concentration of tautomycin, the inhibitory effect also strengthened. When the tautomycin concentration increased to $26.08 \times 10^{-4} \mathrm{~mm}$, no leaf morphology changes were observed.

Effect of tautomycin on the protein phosphatase in S. sclerotiorum As shown in Figure 5, the activity of the PP in S. sclerotiorum was greatly inhibited by tautomycin. At the concentration of $3.26 \times 10^{-4} \mathrm{~mm}$ and $6.52 \times 10^{-4} \mathrm{~mm}$, the activities were inhibited by $41.06 \%$ and $52.03 \%$, respectively.

Table 3 Effect of tautomycin and other related active compounds on myceliogenic germination of sclerotia of Streptomyces sclerotiorum on PDA

\begin{tabular}{|c|c|c|c|c|}
\hline \multirow[b]{2}{*}{ Compounds } & \multicolumn{3}{|c|}{$\begin{array}{c}\text { Number of myceliogenically } \\
\text { germinated sclerotia }(\mathrm{n}=20) \\
\text { after incubation for }\end{array}$} & \multirow{2}{*}{$\begin{array}{c}\text { 96-h germination } \\
\text { rate }(\%)\end{array}$} \\
\hline & $48 \mathrm{~h}$ & $72 \mathrm{~h}$ & $96 \mathrm{~h}$ & \\
\hline Control & 18 & 20 & 20 & \\
\hline Tautomycin & 0 & 0 & 0 & 0 \\
\hline 2,3-Dimethylmaleic anhydride & 0 & 0 & 14 & 70 \\
\hline Diphenylmaleic anhydride & 6 & 14 & 20 & 100 \\
\hline Dimethyl maleate & 2 & 6 & 20 & 100 \\
\hline
\end{tabular}

Abbreviation: PDA, potato dextrose agar.

aThe number of myceliogenically germinated sclerotia is the average of three different repeats.
Effect of tautomycin on the physicochemical changes of S. sclerotiorum

After treating with tautomycin, the hyphal form was changed as described above (Figure 2). From Figure 6, the samples treated with tautomycin solution had higher relative conductivity to the control. The relative conductivity increased with the time of incubation and the increase of tautomycin concentration.

\section{DISCUSSION}

This study revealed that tautomycin and other three compounds with maleic anhydride moiety (2,3-dimethylmaleic anhydride, diphenylmaleic anhydride and dimethyl maleate) could effectively inhibit mycelial growth of $S$. sclerotiorum. The phenyl moiety of phthalic anhydride stabilizes the maleic anhydride functional group, causing the reactivity of the maleic anhydrides to be reduced. This causes the decrease of antifungal activity. Furthermore, the compounds with maleic anhydride and dialkyl structure (2,3-dimethylmaleic anhydride with two methyl groups and diphenylmaleic anhydride with two phenyl groups)

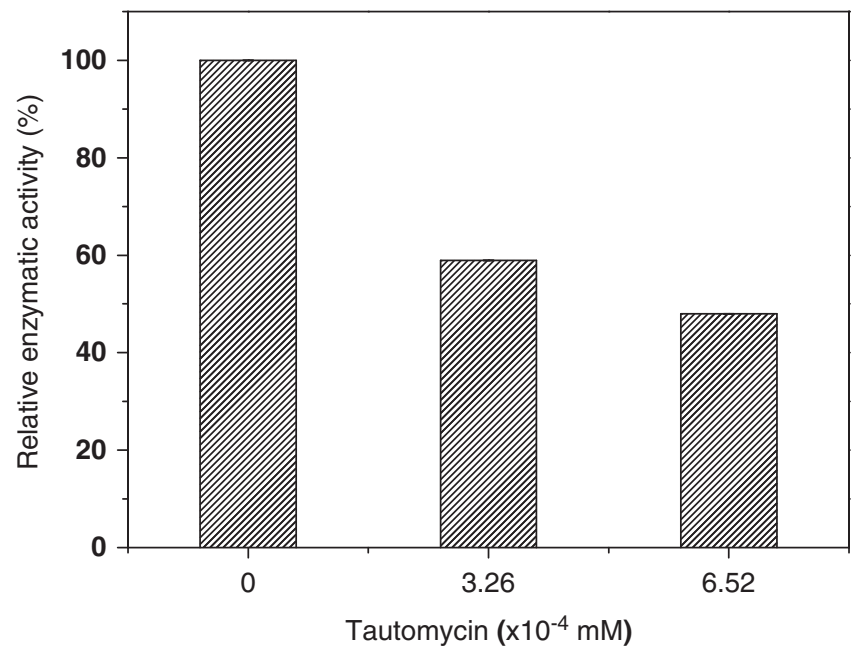

Figure 5 Effect of tautomycin on the activity of protein phosphatase.
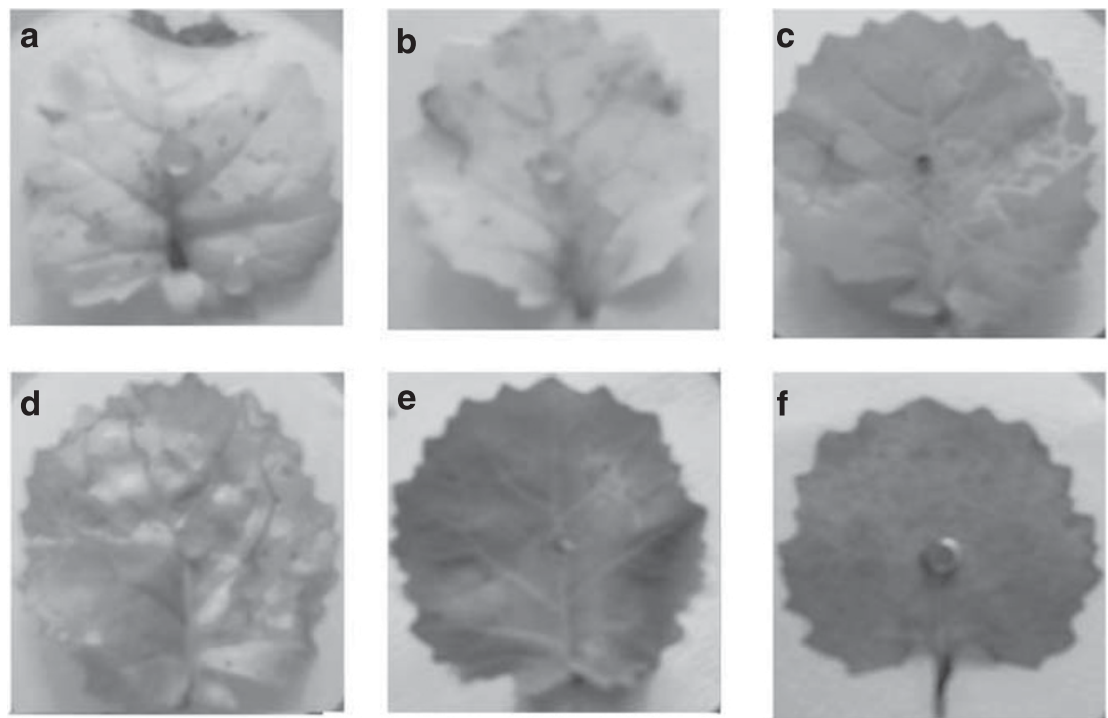

Figure 4 Effect of tautomycin on incidence of leaf blight of oilseed rape caused by $S$. sclerotiorum. Concentration of tautomycin ( $10^{-4} \mathrm{~mm}$ ): a $=0.00$ (control), $\mathbf{b}=3.26, \mathbf{c}=6.52, \mathbf{d}=13.04, \mathbf{e}=26.08$ and $\mathbf{f}=52$.16. A full color version of this figure is available at The Journal of Antibiotics journal online. 


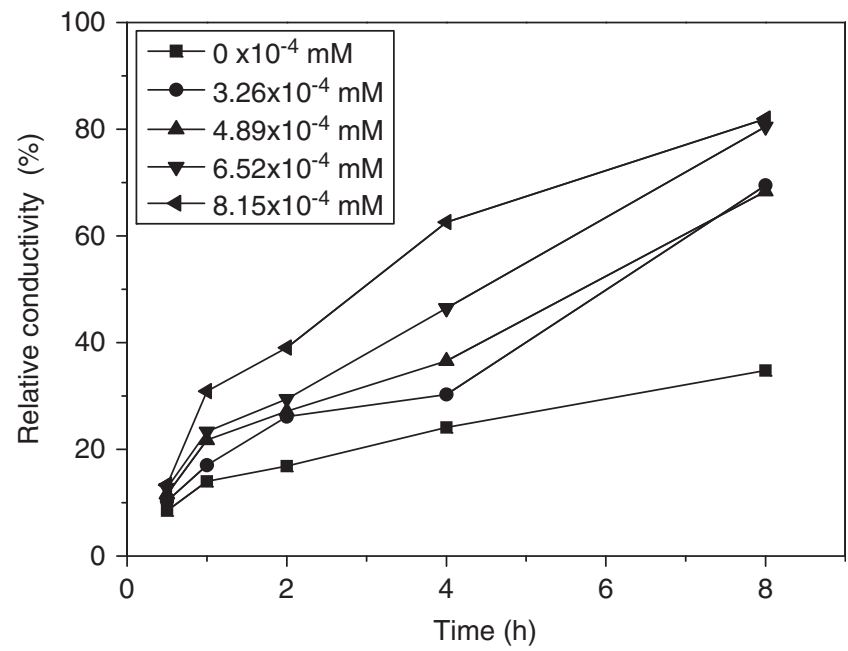

Figure 6 Effect of tautomycin on membrane permeability.

had good activity. The activities of bromomaleic anhydride and phenylmaleic anhydride were lower than those with two groups on the maleic anhydride ring, such as 2,3-dimethylmaleic anhydride, diphenylmaleic anhydride and tautomycin. Hence, the two groups on the maleic anhydride ring may be essential for the antifungal activity. Our results are in accordance with our report ${ }^{5}$ that the compounds with maleic anhydride structure (all with dialkyl structure) have strong biological activities. They are promising candidates to be developed as antifungal agents through further structure modification and combinatorial chemistry.

The present study demonstrated that tautomycin is capable of suppressing the myceliogenic germination of sclerotia. However, 2,3dimethylmaleic anhydride, diphenylmaleic anhydride and dimethyl maleate for $24 \mathrm{~h}$ were less effective than tautomycin against myceliogenic germination. Further work should be taken to make clear that whether tautomycin can be used to control the diseases by suppressing the myceliogenic germination. The in vitro studies demonstrated that treatment of oilseed rape leaves with tautomycin resulted in a suppression of the disease. The results suggest that tautomycin has the potential for suppression of the diseases caused by S. sclerotiorum. The activity of the PP in S. sclerotiorum was inhibited by treating the hyphae with tautomycin solution. This result is in agreement with the literatures. Tautomycin is a good inhibitor of PPs. ${ }^{4,6-8}$ From the Kawamura et al.'s study ${ }^{19}$ of different moieties of tautomycin involved in the inhibition of PP, they suggest that the C22-C26 moiety is essential for inhibition of PP and the anhydride moiety enhances the inhibition. Although the PP was inhibited by tautomycin, whether the inhibition of tautomycin causes the antifungal activity needs further work to verify. Cellular constituents also leaked from S. sclerotiorum cells incubated with tautomycin. These results suggest that the antimicrobial activity of tautomycin is perhaps because of the inhibition of the PP and then a change of membrane permeability.

Tautomycin has good antifungal activity against S. sclerotiorum, including inhibiting mycelial growth, suppressing the myceliogenic germination of sclerotia and suppressing the disease in the in vitro trials. The mechanism of antifungal activity against S. sclerotiorum preliminary investigated that the PP was inhibited by tautomycin and then cellular constituents leaked from cells. However, the high toxicity of tautomycin limits its application in agriculture. From our preliminary study, the antifungal activity of tautomycin against $S$. sclerotiorum was dependent on the maleic anhydride moiety. Further studies will be conducted to modify the structure of tautomycin with the maleic anhydride as the core structure to keep or improve the antifungal activity and lower the toxicity. Therefore, tautomycin and its derivatives have the potential to be developed as the antifungal agent against S. sclerotiorum. Further studies on tautomycin and its derivatives, such as phytotoxicity tests and field experiments, are required to determine its potential as a commercial fungicide.

\section{ACKNOWLEDGEMENTS}

This study received financial support from the Major State Basic Research Development Program of China (973 Program) (No. 2010CB126101) and Zhejiang Provincial Key Special Projects (No. 2007C12088).

1 Boland, G. J. \& Hall, R. Index of plant hosts of Sclerotinia sclerotiorum. Can. J. Plant. Pathol 16, 93-108 (1994).

2 Fuller, P., Coyne, D. \& Steadman, J. Inheritances of resistance to white mold disease in a diallel cross of dry beans. Crop. Sci. 24, 929-933 (1984).

3 Cheng, X. C. et al. A new antibiotic, tautomycin. J. Antibiot. 40, 907-909 (1987).

4 Cheng, X. C., Ubukata, M. \& Isono, K. The structure of tautomycin, a dialkylmaleic anhydride antibiotic. J. Antibiot. 43, 809-819 (1990).

5 Chen, X. L., Zheng, Y. G. \& Shen, Y. C. Natural products with maleic anhydride structure: nonadrides, tautomycin, chaetomellic anhydride, and other compounds. Chem. Rev. 107, 1777-1830 (2007).

6 Mackintosh, C. \& Klumpp, S. Tautomycin from the bacterium Streptomyces verticillatus. Another potent and specific inhibitor of protein phosphatases 1 and $2 \mathrm{~A}$. FEBS. Lett. 277, 137-140 (1990).

7 Mackintosh, C., Lyon, G. D. \& Mackintosh, R. W. Protein phosphatase inhibitors activate anti-fungal defense responses of soybean cotyledons and cell cultures. Plant. J. 5, 137-147 (1994).

8 Ubukata, M., Koshino, H., Yamasahi, C. \& Fujita, K. I. A pharmacophore model of tautomycin an, inhibitor of protein phosphatases 1 and 2A. J. Antibiot. 50, 801-807 (1997).

9 Chen, X. L., Zheng, Y. G. \& Shen, Y. C. Bioassay method for the quantitative determination of tautomycin in the fermentation broth with Sclerotinia sclerotiorum. J. Rapid. Meth. Autom. Microb. 16, 199-209 (2008).

10 Ubukata, M., Cheng, X. C., Uzawa, J. \& Isono, K. Biosynthesis of the dialkylmaleic anhydride-containing antibiotics, tautomycin and tautomycetin. J. Chem. Soc. 1, 2399-2404 (1995).

11 Oikawa, M., Oikawa, H. \& Ichihara, A. Synthetic study on tautomycin. Stereocontrolled synthesis of C (1)-C (18) fragment using a strategy of selective reduction of spiroketal. Tetrahedron. Lett. 34, 4797-4800 (1993).

12 Futagawa, M., Rimando, A. M., Tellez, M. R. \& Wedge, D. E. pH modulation of zopfiellin antifungal activity to Colletotrichum and Botrytis. J. Agric. Food. Chem. 50, 7007-7012 (2002).

13 Futagawa, M., Wedge, D. E. \& Dayan, F. E. Physiological factors influencing the antifungal activity of zopfiellin. Pestic. Biochem. Physiol. 73, 87-93 (2002).

14 Amagasa, T., Paul, R. N., Heitholt, J. J. \& Duke, S. O. Physiological-effects of cornexistin on lemna-pausicostata. Pestic. Biochem. Physiol. 49, 37-52 (1994).

15 Fields, S. C., Mireles-Lo, L. \& Gerwick, B. C. Hydroxycornexistin: a new phytotoxin from Paecilomyces variotii. J. Nat. Prod. 59, 698-700 (1996).

16 Fang, Z. D. Research Methodology for Plant Diseases 8-12, (3rd Ed., Chinese Agriculture Press: Beijing, 1998).

17 Pallen, C. J. \& Wang, J. H. Calmodulin-stimulated dephosphorylation of $p$-nitrophenyl phosphate and free phosphotyrosine by calcineurin. J. Biol. Chem. 258, 8550-8553 (1983).

18 Kobno, Y., Waanabe, M. \& Hosokawa, D. Studies on the physiogical changes in the rice plant infected with X. oryzae. Ann. Phytopath. Sor. Japan 47, 555-561 (1981).

19 Kawamura, T. et al. Different moieties of tautomycin involved in protein phosphatase inhibition and induction of apoptosis. Biochem. Pharmacol. 55, 995-1003 (1998). 